\title{
A Brief History of IFIP WG 8.2 Research: The People, the Places, the Methods, and the Issues
}

\author{
Nancy L. Russo ${ }^{1}$ and Michael D. Myers ${ }^{2}$ \\ ${ }^{1}$ Northern Illinois University, \\ DeKalb, Illinois, USA \\ ${ }^{2}$ University of Auckland, \\ Auckland, New Zealand
}

This panel will present a high-level examination of the research papers that have appeared in proceedings of the International Federation for Information Processing Working Group 8.2, which addresses the interaction between information systems and the organization. More specifically, Working Group 8.2 is "concerned with the generation and dissemination of descriptive and normative knowledge about the development and use of information technologies in organizational contexts," as described in its statement of scope (www.ifipwg82.org). Both information systems and organizations are viewed broadly within the context of research covered by the Working Group.

The Working Group held its first conference in 1979. A total of 26 conferences have been organized by the Working Group, including four organized jointly with other working groups, prior to the current conference. During these conferences spanning 30 years, approximately 500 research papers have been presented.

Following the approach used by Dwivedi and other colleagues (e.g., Dwivedi and Kuljis 2008; Dwivedi et al. 2009) to study contents of various journals and the research output of IFIP WG 8.6 (published elsewhere in this Proceedings), data on a number of variables including author information and keywords were collected from all available proceedings of past conferences of IFIP WG 8.2.

Panel participants will discuss the outcome of the analysis of this data, including changing trends in research approaches and topics, the people and universities most represented, and other factors of interest.

\section{References}

Dwivedi, Y.K., Kuljis, J.: Profile of IS Research Published in the European Journal of Information Systems. European Journal of Information Systems 17(6), 678-693 (2008)

Dwivedi, Y.K., Lal, B., Mustafi, N., Williams, M.D.: Profiling a Decade of Information Systems Frontiers' Research. Information Systems Frontiers 11(1), 87-102 (2009) 